\title{
Article \\ Refrigeration of COVID-19 Vaccines: Ideal Storage Characteristics, Energy Efficiency and Environmental Impacts of Various Vaccine Options
}

\author{
Alexandre F. Santos ${ }^{1,2}$, Pedro D. Gaspar 1,3® and Heraldo J. L. de Souza 2,* \\ 1 Department of Electromechanical Engineering, University of Beira Interior, 6201-001 Covilhã, Portugal; \\ d1682@ubi.pt (A.F.S.); dinis@ubi.pt (P.D.G.) \\ 2 FAPRO-Professional College, Curitiba 80230-040, Brazil \\ 3 C-MAST-Centre for Mechanical and Aerospace Science and Technologies, 6201-001 Covilhã, Portugal \\ * Correspondence: heraldo@escolaprofissional.com.br; Tel.: +(55)-41-999748928
}

Citation: Santos, A.F.; Gaspar, P.D.; de Souza, H.J.L. Refrigeration of COVID-19 Vaccines: Ideal Storage Characteristics, Energy Efficiency and Environmental Impacts of Various Vaccine Options. Energies 2021, 14, 1849. https://doi.org/10.3390/ en14071849

Academic Editor: Carlo Renno

Received: 19 February 2021

Accepted: 23 March 2021

Published: 26 March 2021

Publisher's Note: MDPI stays neutral with regard to jurisdictional claims in published maps and institutional affiliations.

Copyright: (c) 2021 by the authors. Licensee MDPI, Basel, Switzerland. This article is an open access article distributed under the terms and conditions of the Creative Commons Attribution (CC BY) license (https:// creativecommons.org/licenses/by/ $4.0 /)$.

\begin{abstract}
This article considers the ideal storage conditions for multiple vaccine brands, such as Pfizer, Moderna, CoronaVac, Oxford-AstraZeneca, Janssen COVID-19 and Sputnik V. Refrigerant fluid options for each storage condition, thermal load to cool each type of vaccine and environmental impacts of refrigerants are compared. An energy simulation using the EUED (energy usage effectiveness design) index was developed. The Oxford-AstraZeneca, Janssen COVID-19 and CoronaVac vaccines show 9.34-times higher energy efficiency than Pfizer. In addition, a TEWI (total equivalent warming impact) simulation was developed that prioritizes direct environmental impacts and indirect in refrigeration. From this analysis, it is concluded that the cold storage of Oxford-AstraZeneca, Janssen COVID-19 and CoronaVac vaccines in Brazil generates 35-times less environmental impact than the Pfizer vaccine.
\end{abstract}

Keywords: SARS-CoV-2; vaccines; refrigeration; energy consumption; GWP; TEWI; EUED; environmental impact

\section{Introduction}

Among the various controversial issues regarding SARS-CoV-2 are the questions of vaccine availability and logistics [1]. There are several different cold storage conditions between multiple brands. In the United States of America (USA) and Europe, the first approved vaccines were Pfizer-BioNTech and Moderna [2]. In Brazil, the first vaccines approved were CoronaVac and Oxford-AstraZeneca [3]. In Argentina, the first approved vaccine was Sputnik V. The Johnson \& Johnson vaccine was the last vaccine to be approved both in the USA and Europe. It is a fact that the vaccine itself to be produced goes through several unique principles of refrigeration and clean rooms. One of the characteristics of these clean rooms is the BSL-03 (Biosafety Security Level) [4], with cascades of air pressure that are essential to ensure the safety of the users. After all the work to develop and produce the vaccines, however, they face cold storage and distribution issues. Thus, assessment of the electricity consumption and the environmental impacts helps each country to make the appropriate decision about which brand of vaccine to choose. In doing so, each must consider the operational costs and environmental factors produced during their cold storage [5].

According to Pfizer [6], the brand's vaccine needs a storage temperature of $-70{ }^{\circ} \mathrm{C} \pm$ $10^{\circ} \mathrm{C}$. As soon as a vaccination center receives a thermal sender with Pfizer's vaccines, it has three storage options:

- Ultra-low-temperature freezers, which are available on the market and can extend service life by up to six months; 
- Pfizer thermal shipper, in which doses will arrive, which can be used as temporary storage units, recharging with dry ice every five days for up to 30 days of storage;

- Refrigeration units commonly available in hospitals. The vaccine can be stored for five days, refrigerated at $2-8{ }^{\circ} \mathrm{C}$.

After storage for up to 30 days in Pfizer's thermal shipper, vaccination centers can transfer the vials to $2-8{ }^{\circ} \mathrm{C}$ storage conditions for an additional five days, for a total of up to 35 days. Once defrosted and stored under $2-8{ }^{\circ} \mathrm{C}$ conditions, the bottles cannot be refrozen or stored under freezing conditions.

The various storage options for vaccination centers allow equitable access to Pfizer's vaccine in areas with different infrastructure.

According to the Centers for Disease Control and Prevention (CDC) of the USA, the characteristics of the Moderna vaccine storage are [7]:

- The vaccine will arrive frozen between $-25^{\circ} \mathrm{C}$ and $-15^{\circ} \mathrm{C}$ and needs to be stored at the same temperature. After defrosting, the vaccine may be thawed in the refrigerator or at room temperature [8];

- $\quad$ Refrigerator: $2^{\circ} \mathrm{C}$ to $8{ }^{\circ} \mathrm{C}$ for $2 \mathrm{~h}$ and $30 \mathrm{~min}$;

- Room temperature: between $15^{\circ} \mathrm{C}$ and $25^{\circ} \mathrm{C}$ for $1 \mathrm{~h}$.;

- Unpunctured vials may be kept between $8{ }^{\circ} \mathrm{C}$ and $25^{\circ} \mathrm{C}$ for up to $12 \mathrm{~h}$;

- Thawed vaccines cannot be refrozen;

- Vaccine vials may be stored in the refrigerator between $2{ }^{\circ} \mathrm{C}$ and $8{ }^{\circ} \mathrm{C}$ for up to 30 days before vials are punctured. After 30 days, any remaining vials should be removed from the refrigerator and discarded following manufacturer and jurisdiction guidance on proper disposal [7].

Zeng [9] stated that the CoronaVac vaccine can be stored at normal refrigerator temperatures-that is, $2{ }^{\circ} \mathrm{C}$ to $8{ }^{\circ} \mathrm{C}$ - and it remains valid for a period of up to three years, offering an advantage for distribution in places where access to refrigeration is a challenge.

The British government's instructions regarding the Oxford-AstraZeneca vaccine are [10]:

- It can be stored in a refrigerator $\left(2{ }^{\circ} \mathrm{C}\right.$ to $\left.8^{\circ} \mathrm{C}\right)$;

- It should not freeze;

- After the first dose is withdrawn, the vaccine should be used as soon as possible and within six hours. During use, it can be stored from $2{ }^{\circ} \mathrm{C}$ to $25^{\circ} \mathrm{C}$.

The Sputnik $\mathrm{V}$ vaccine has a physical robustness that allows storage at temperatures near $-18{ }^{\circ} \mathrm{C}$, which is feasible for many supply chains [11].

According to the CDC of the USA, the storage temperature of the Janssen COVID-19 vaccine produced by Johnson \& Johnson is between $2^{\circ} \mathrm{C}$ and $8{ }^{\circ} \mathrm{C}$ [12].

The lower-limit storage conditions of the different SARS-CoV-2 vaccines are shown in Table 1, since these will be the values used for further calculations.

Table 1. Vaccine storage temperatures.

\begin{tabular}{cc}
\hline Vaccine & Storage Temperature ${ }^{\circ} \mathbf{C}$ \\
\hline Pfizer-BioNTech & -70 \\
Moderna & -25 \\
CoronaVac & 2 \\
Oxford-AstraZeneca & 2 \\
Sputnik V & -18 \\
Janssen COVID-19 & 2 \\
\hline
\end{tabular}

Knowing the importance of electric energy and the environmental impacts that cold storage can generate, this paper aims to address the following research questions: (1) How can the environmental impact of cold storage be measured? (2) Which refrigerant gases are commonly used for these temperatures? (3) What suggestions can be made regarding 
the reduction of environmental impacts, since, with the growth of new types of viruses, vaccines will become more frequent?

\section{Materials and Methods}

A comparison of the energy consumption of vaccine cold storage systems requires the determination of their cooling load. For example, equipment at standard capacity for 100,000 doses has the following characteristics [13]:

- Height, $H=2050 \mathrm{~mm}$;

- $\quad$ Length, $L=1600 \mathrm{~mm}$;

- $\quad$ Width, $W=790 \mathrm{~mm}$;

- Gross volume, $V_{\mathrm{g}}=2.59 \mathrm{~m}^{3}$;

- Useful volume, $V_{\mathrm{u}}=1.05 \mathrm{~m}^{3}$;

- Estimated dose capacity, $n=100,000$;

- Dose Volume, $V_{\mathrm{d}}=0.3 \mathrm{ml}\left(=3.0 \times 10^{-7} \mathrm{~m}^{3}\right)$.

The equipment walls have a minimum thermal insulation panel depth of $70 \mathrm{~mm}$ comprising thermal insulation panels with expanded injected polyurethane free of CFC (chlorofluorocarbons). The front doors are glassed. The Coolpack software was used to determine the cooling load using the cold storage temperatures in Table 1 with an ambient temperature of $24^{\circ} \mathrm{C}$. The results of the cooling load are shown in Table 2 [14]. It is important to point out that cold room temperatures were used for the doses entering the refrigeration equipment. Additionally, the inlet vaccine temperatures (see Table 1) lead to multiple air changes in $24 \mathrm{~h}$; with an air change factor, ACF $=43.5$.

Table 2. Vaccine thermal loads.

\begin{tabular}{cccc}
\hline Vaccine & $\begin{array}{c}\text { Inlet Vaccine } \\
\text { Temperature }\left({ }^{\circ} \mathbf{C}\right)\end{array}$ & $\begin{array}{c}\text { Cold Room } \\
\text { Temperature }\left({ }^{\circ} \mathbf{C}\right)\end{array}$ & $\begin{array}{c}\text { Cooling Load } \\
(\mathbf{K w})\end{array}$ \\
\hline Pfizer-BioNTech & -60 & -70 & 2.23 \\
Moderna & -15 & -25 & 1.38 \\
CoronaVac & 8 & 2 & 1.02 \\
Oxford-AstraZeneca & 8 & 2 & 1.02 \\
Sputnik V & -12 & -18 & 1.28 \\
Janssen COVID-19 & 8 & 2 & 1.02 \\
\hline
\end{tabular}

The coefficient of performance (COP), the ratio of cooling provided to electric energy consumption, is the most common parameter for comparing the performance of refrigeration equipment. Specifically, ASHRAE 90.1-2019 (Energy Standard for Buildings Except Low-Rise Residential Buildings) [15] dictates the energy efficiency parameters. There are some parameters for commercial refrigerators, commercial freezers and refrigeration. The specific energy consumption given in $\mathrm{kWh}$ /day is based on the AHRI 1201-2013 standard. However, this AHRI standard does not specify a range for vaccine equipment. Thus, one of the goals of this study is to create a method to compare this type of equipment, the Vaccine EUED (energy usage effectiveness design), and to compare the greenhouse effect to Vaccine TEWI (Total Equivalent Warming Impact) [16]. To compare the energy efficiency of cold vaccine storage equipment, it is necessary to gauge some parameters, such as differentiating between air intake and condensation temperature, and differentiating between storage temperature and evaporation temperature. In addition to the isentropic coefficient of the compressor, the AHRI 210/240-2017 [17] normally uses the difference between the air inlet and condensation temperatures of $10^{\circ} \mathrm{C}$, due to the vaccine refrigerators being located in acclimatized places. The ANSI/ASHRAE Standard 72-2018 considers that the intake of air in the condenser must be $24^{\circ} \mathrm{C}$ at room temperature [18]. Table 3 includes the temperature values and parameters for each type of vaccine. 
Table 3. Vaccines and equipment characteristics.

\begin{tabular}{cccccc}
\hline Vaccine & $\begin{array}{c}\text { Inlet Condenser } \\
\text { Temperature }\left({ }^{\circ} \mathbf{C}\right)\end{array}$ & $\begin{array}{c}\text { RFCT } \\
\left({ }^{\circ} \mathbf{C}\right)\end{array}$ & $\begin{array}{c}\text { Cold Room } \\
\text { Temperature }\left({ }^{\circ} \mathbf{C}\right)\end{array}$ & $\begin{array}{c}\text { RFET } \\
\left({ }^{\circ} \mathbf{C}\right)\end{array}$ & EFISEN \\
\hline Pfizer-BioNTech & 24 & 34 & -70 & -80 & 0.7 \\
Moderna & 24 & 34 & -25 & -35 & 0.7 \\
CoronaVac & 24 & 34 & 2 & -8 & 0.7 \\
Oxford-AstraZeneca & 24 & 34 & 2 & -8 & 0.7 \\
Sputnik V & 24 & 34 & -18 & -28 & 0.7 \\
Janssen COVID-19 & 24 & 34 & 2 & -8 & 0.7 \\
\hline
\end{tabular}

Note: RFCT = Refrigerant fluid condensation temperature. RFET = Refrigerant fluid evaporation temperature. EFISEN = Isentropic efficiency.

After determining the parameters for measuring the COP, it is important to choose the refrigerant considering (1) the Montreal protocol encouraging the use of zero ozone depletion potential (ODP) refrigerants, disregarding the phasing out of refrigerants such as R-12 and R-502 [19]; and (2) the Kigali protocol [20] encouraging the use of refrigerants with low Global Warming Potential (GWP). For example, the R-404A has a high GWP index $(\mathrm{GWP}=3922)$, while R-134A has a GWP $=1430$. Although natural fluids have low GWP, they are not used in vaccine refrigerators. For example, an ammonia system is very complex for small systems, besides its dangerous toxicity [21].

The guideline for establishing or improving primary and intermediate vaccine stores set by the World Health Organization (WHO) [22] states that R134A is often used for $+4{ }^{\circ} \mathrm{C}$ cold rooms but is not suitable for $-20^{\circ} \mathrm{C}$ freezer rooms. Various alternative gases are available for this purpose, among them the gas R404A. However, it is already being phased out (virgin R404A can no longer be used in new equipment, but recovered or reclaimed R404A can be used until the end of 2030) and superseded by new, low-GWP refrigerants such as R454C, R455A and R1234yf for small packaged equipment and medium-sized multi-compressor equipment, although it is still used in a number of systems.

The most used refrigerants were prioritized, specifically those with medium evaporation temperatures. Thus, the refrigerant used in the refrigeration systems of the CoronaVac, Oxford-AstraZeneca and Janssen COVID-19 vaccines is the R-134A. The refrigerant R-449A (low GWP compared to R-404A) is used in the refrigeration system of Moderna and Sputnik V. For the Pfizer-BioNTech vaccine, the refrigerant R-508B, with special refrigerant and ultra-low evaporation temperature applications associated with the R-449A, is used. Although studies have already predicted the use of low-GWP refrigerants such as the R-449A, in practice, in Brazil, R-404A is still widely used. As a result, a simulation with both options will be developed. Table 4 shows the refrigerant selected for the refrigeration system of each vaccine due to thermal requirements. The table also shows the GWP, the refrigerant load required, the equivalent $\mathrm{CO}_{2}$ emissions and the $\mathrm{CO}_{2}$ emissions when $\mathrm{R}-404 \mathrm{~A}$ is used instead of low-GWP R-449A.

Table 4. Vaccines and GWP.

\begin{tabular}{cccccc}
\hline Vaccine & Refrigerant & GWP & $\begin{array}{c}\text { Refrigerant Load } \\
(\mathbf{k g})\end{array}$ & $\begin{array}{c}\mathbf{C O}_{2} \text { Emissions } \\
(\mathbf{R} \text { 449A) }\end{array}$ & $\begin{array}{c}\mathbf{C O}_{2} \text { Emissions } \\
(\mathbf{k g})\end{array}$ \\
\hline Pfizer-BioNTech & R-508B \& R-449A & $13,396 \& 1430$ & $0.15+0.45$ & 2652.90 & 3774.30 \\
Moderna & R-449A & 1397 & 0.405 & 565.78 & 1588.41 \\
CoronaVac & R-134A & 1430 & 0.27 & 386.10 & 386.10 \\
Oxford-AstraZeneca & R-134A & 1430 & 0.27 & 386.10 & 386.10 \\
Sputnik V & R-449A & 1397 & 0.37 & 516.89 & 1451.14 \\
Janssen COVID-19 & R-134A & 1430 & 0.27 & 386.10 & 386.10 \\
\hline
\end{tabular}

The refrigerant loads were simulated in FAPRO Laboratories in Curitiba-Paraná, Brazil. Figure 1 shows the differences between the environmental impact in terms of $\mathrm{CO}_{2}$ emissions, assuming the use of R-404A initial refrigerant load. Despite the heat load for the Pfizer-BioNTech vaccine, it is 2.2-times greater than that of Oxford-AstraZeneca, CoronaVac and Janssen COVID-19 (see Table 2). The environmental impact due to the 
refrigerant, which is required to comply with the needed storage temperature, has a difference of almost 10 times.

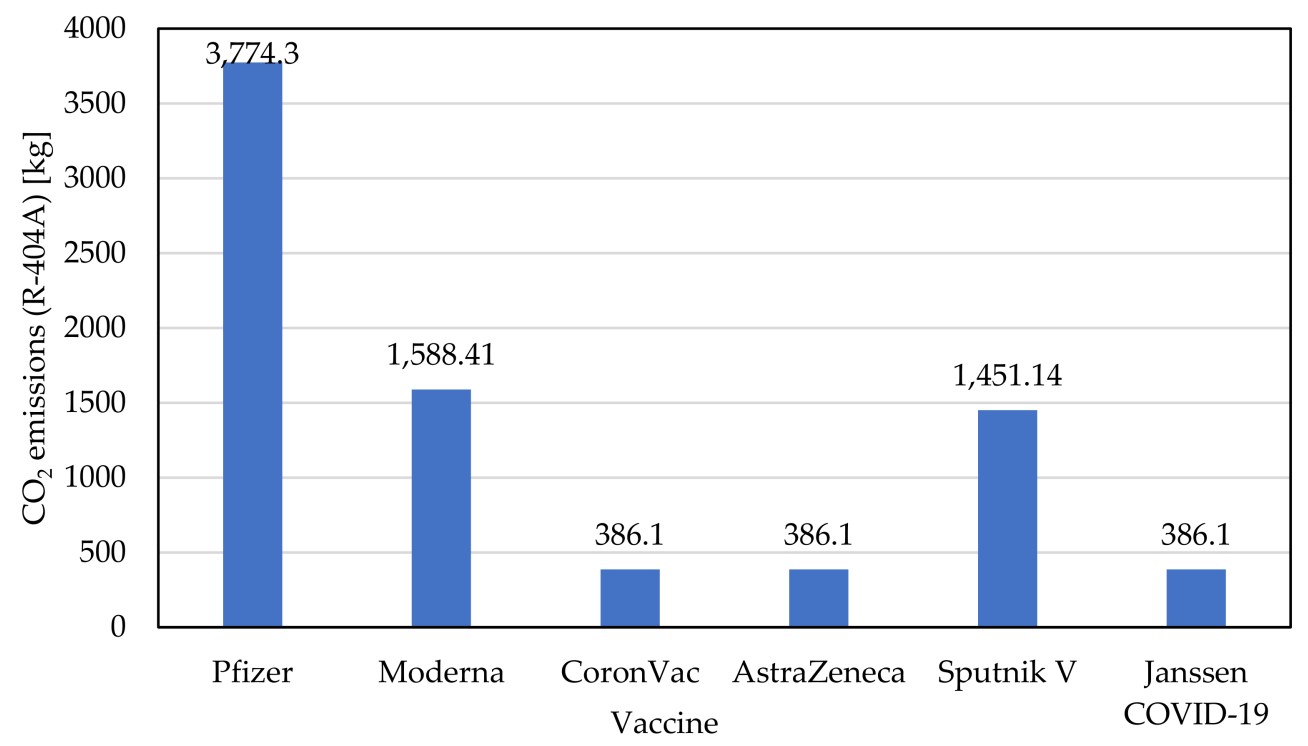

Figure 1. Environmental impact in terms of $\mathrm{CO}_{2}$ emissions, assuming the use of R-404A initial refrigerant load.

With the thermal requirements and refrigerants chosen, the next step is the measurement of the COP. Ultra-low-temperature refrigerators require special refrigerants. The refrigerant R-508B is used in this simulation. The Chemours software, Expert 1.0, was used for this simulation [23]. Figure 2 shows the $\mathrm{COP}$ of the refrigeration system with condenser fans and an evaporator for vaccines.

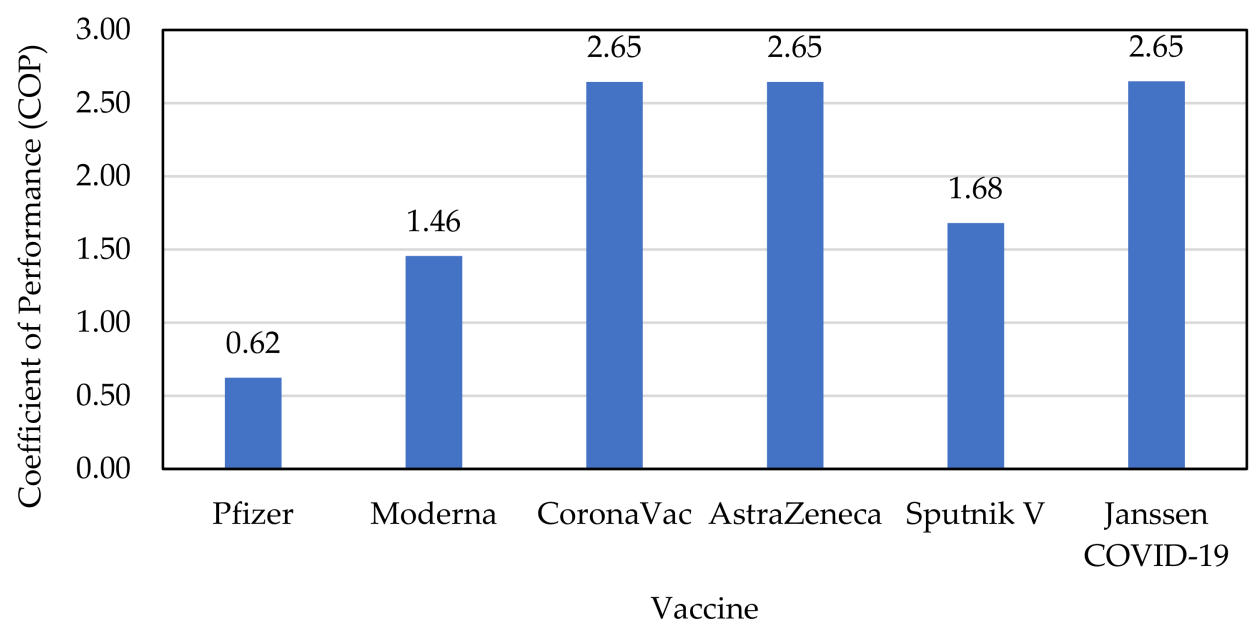

Figure 2. COP of refrigeration system with condenser fans and evaporator for vaccines.

\subsection{Vaccine Energy Usage Effectiveness Design (EUED)}

The energy usage effectiveness design (EUED) index was initially proposed to measure the energy efficiency in datacenters (DC) [24-29].

The EUED index provides a more comprehensive and global view of the energy consumption as it emphasizes the environment [30-32]. This analysis provided by the index involves all natural parameters of a region, considering the location where a DC is to be installed (air dry and wet bulb temperatures, air dew point temperature and soil 
temperature). The EUED given by Equation (1) can be used in the design phase to predict a measurement of the DC efficiency.

$$
\text { EUED }=\frac{\text { Total energy with entalpic variations }[\mathrm{kWh} / \mathrm{yr}]}{\text { Specific consumed energy by equipment }[\mathrm{kWh} / \mathrm{yr}]}
$$

The EUED index uses the climatic data of $8760 \mathrm{~h}$ per year. It stipulates psychrometric conditions for the use of free cooling, evaporative systems and variable COPs. This index is adapted for vaccine refrigerators. It is important to note that these refrigerators are usually located in climatized facilities, so a constant condensation temperature was used. Some operational particularities were determined during the tests developed in the FAPRO laboratory. First, the price of R-508B is extremely high and it is not available in refrigeration stores in Brazil. Second, there is extreme risk associated with working at ultra-low-temperatures and this required the use of special protective clothing to avoid work accidents. Additionally, the experimental tests determined that the compressor was used $60 \%$ of the time. This value arose when the cooling loads of the vaccines from the minimum to the maximum limits were considered. For example, for a CoronaVac, OxfordAstraZeneca and Janssen COVID-19 vaccine being stored at $+8{ }^{\circ} \mathrm{C}$, and maintained at $+2{ }^{\circ} \mathrm{C}$, after thermal equilibrium, the thermal load is only given by thermal conduction and infiltration. The Vaccine EUED is defined by Equation (2):

$$
\text { Vaccine EUED }=\left(\frac{\text { Thermal Load }[\mathrm{kW}]}{\text { COPcomplete }\left[\frac{\mathrm{kW}}{\mathrm{kW}}\right]}\right) \cdot \text { Load Factor }(\%) \cdot 8760 \text { hours }
$$

Considering the thermal load values shown in Table 2, the COP determined and shown in Figure 2, a compressor load factor of 0.6 and $8760 \mathrm{~h}$ of operation, the Vaccine EUED index, representing the energy consumption for each vaccine refrigeration system during a year, is shown in Figure 3.

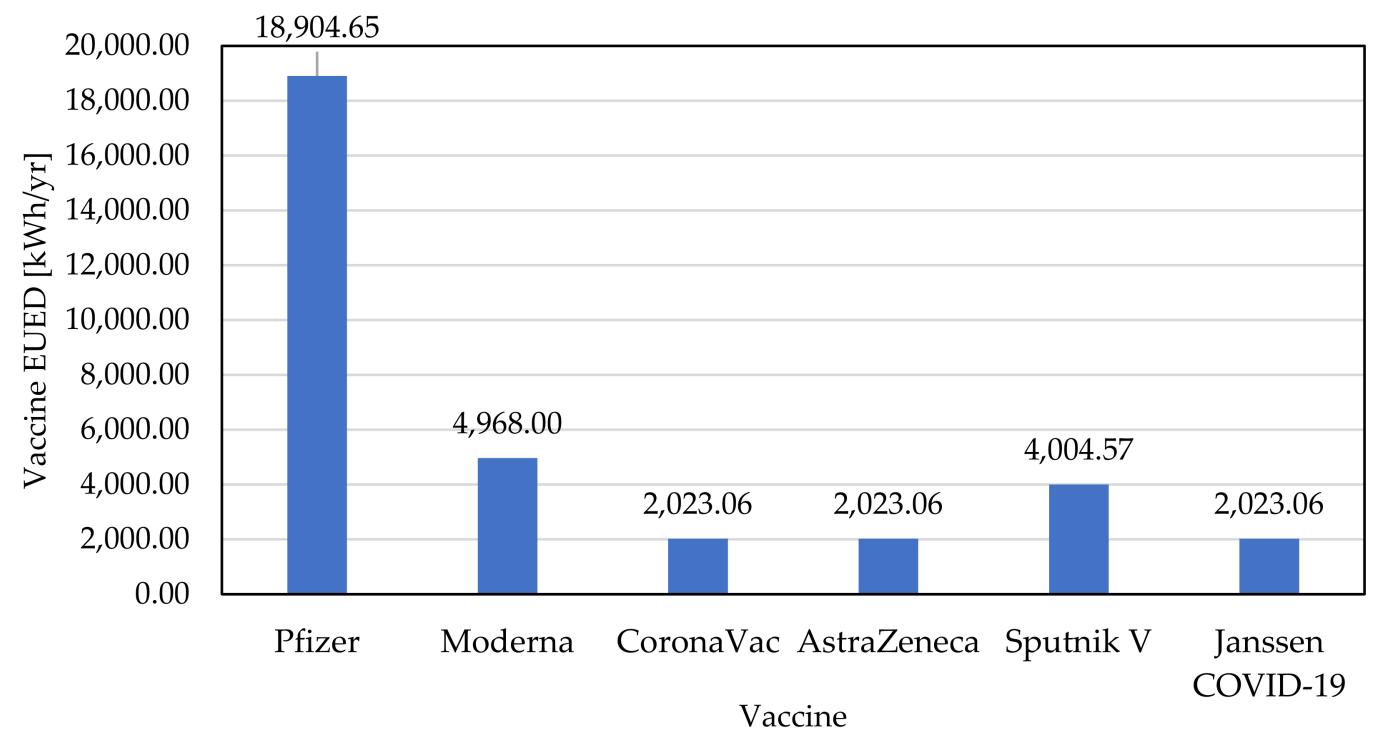

Figure 3. Vaccine Energy Usage Effectiveness Design (EUED) index.

It is important to note that the difference between vaccines is substantial. For example, the refrigeration system for a vaccine from Pfizer-BioNTech consumes nine-times more energy than the system for a vaccine from Oxford-AstraZeneca, CoronaVac or Janssen COVID-19. 


\subsection{Vaccine Total Equivalent Warming Impact (TEWI)}

Total equivalent warming impact (TEWI) is a metric of the global warming impact of equipment based on the total emissions related to the global warming impact (GWP) during the operation of the equipment and the removal of operational fluids at the end of life. TEWI takes into account both direct and indirect emissions [33]:

- Direct emission-refrigerant released during the lifetime of the equipment, including losses not recovered on the final disposal;

- Indirect emission - the impact of $\mathrm{CO}_{2}$ emissions from fossil fuels used to generate the electric energy that is used in the operation of the equipment throughout its lifetime. The method of calculating TEWI is given by Equations (3) and (4):

TEWI $=$ GWP(direct, refrigerant leaks including EOL $)+$ GWP(indirect, operation $)$

$$
\mathrm{TEWI}=\left(\mathrm{GWP} \cdot L_{\text {annual }} \cdot n\right)+\mathrm{GWP} \cdot m \cdot\left(1-\alpha_{\text {recovery }}\right)+\left(E_{\text {annual }} \cdot \beta \cdot n\right)
$$

where:

$\mathrm{EOL}=$ end of life;

$\mathrm{GWP}=$ global warming potential of refrigerant, rel. to $\mathrm{CO}_{2}\left(\mathrm{GWP} \mathrm{CO}_{2}=1\right)$;

$L_{\text {annual }}=$ leakage rate p.a. $(\mathrm{kg})$;

$n=$ system operating life (yrs);

$m=$ refrigerant charge $(\mathrm{kg})$;

$\alpha_{\text {recovery }}=$ recovery $/$ recycling factor from 0 to 1 ;

$E_{\text {annual }}=$ energy consumption per year (kWh p.a.);

$\beta=$ indirect emission factor $\left(\mathrm{kg} \mathrm{CO}_{2} / \mathrm{kWh}\right)[9]$.

The results point out that refrigerant fluids have proportionally a greater impact in Brazil than in other important world markets.

The indirect emission factor, $\beta$, given in $\mathrm{kg} \mathrm{CO}_{2} / \mathrm{kWh}$, varies according to the energy matrix. For example, in Brazil, the matrix of the energy system is shared in the same transmission for the whole country. According to National Energy Balance Brazil (BEN), Brazil emits $0.088 \mathrm{~kg} \mathrm{CO}_{2} / \mathrm{kWh}$ [34]. According to the Energy Information Administration (EIA) [35], the United States of America emits $0.417 \mathrm{~kg} \mathrm{CO}_{2} / \mathrm{kWh}$. The Vaccine TEWI index uses TEWI concepts in addition to the Vaccine EUED index, for a 10-year lifecycle, is given by Equation (5) [36]:

$$
\text { Vaccine TEWI }=\text { GWP }(\text { direct leaks including EOL })+(\text { yearly EUED } \beta \cdot 10)
$$

The results for the Vaccine TEWI of the refrigeration systems for storing some types of COVID-19 vaccines in Brazil and in the USA are shown in Table 5 applying Equation (5).

\begin{tabular}{|c|c|c|c|c|c|c|c|}
\hline Vaccine & Refrigerant & $\begin{array}{c}\text { TEWI } \\
\text { (Direct) }\end{array}$ & $\begin{array}{c}\text { EUED } \\
(\mathrm{kWh} / \mathrm{yr})\end{array}$ & $\begin{array}{c}\text { TEWI } \\
\text { (Ind. USA) }\end{array}$ & $\begin{array}{c}\text { TEWI } \\
\text { (Ind. USA) }\end{array}$ & $\begin{array}{c}\text { TEWI } \\
\text { (Total Brazil) }\end{array}$ & $\begin{array}{c}\text { TEWI } \\
\text { (Total USA) }\end{array}$ \\
\hline Pfizer-BioNTech & R-508B \& R-449A & 4111.99 & $18,904.65$ & $16,636.09$ & $78,832.39$ & $20,748.09$ & $82,944.39$ \\
\hline Moderna & R-449A & 876.97 & 4968.00 & 4371.84 & $20,716.56$ & 5248.81 & $21,593.53$ \\
\hline CoronaVac & $\mathrm{R}-134 \mathrm{~A}$ & 598.45 & 2023.06 & 1780.29 & 8436.16 & 2378.75 & 9034.62 \\
\hline Oxford-AstraZeneca & $\mathrm{R}-134 \mathrm{~A}$ & 598.45 & 2023.06 & 1780.29 & 8436.16 & 2378.75 & 9034.62 \\
\hline Sputnik V & $\mathrm{R}-449 \mathrm{~A}$ & 801.18 & 4004.57 & 3524.02 & $16,699.06$ & 4325.20 & $17,500.24$ \\
\hline Janssen COVID-19 & $\mathrm{R}-134 \mathrm{~A}$ & 598.45 & 2023.06 & 1780.29 & 8436.16 & 2378.75 & 9034.62 \\
\hline
\end{tabular}

Table 5. Direct and indirect TEWI of each vaccine refrigeration system for Brazil and the USA.

Figure 4 compares the Vaccine TEWI of a refrigerator to store 100,000 vaccine doses during the equipment lifecycle (10 years), considering a $60 \%$ of use factor. Given the difference between the TEWI values of Brazil and the USA, it is verified that the energy mix has a great influence on the environmental impacts. For example, a refrigerator to cold-store the Pfizer-BioNTech vaccine in the USA will emit almost 35-times more $\mathrm{CO}_{2}$ 
than that of a refrigerator to cold-store the Oxford-AstraZeneca, CoronaVac or Janssen COVID-19 vaccine in Brazil.

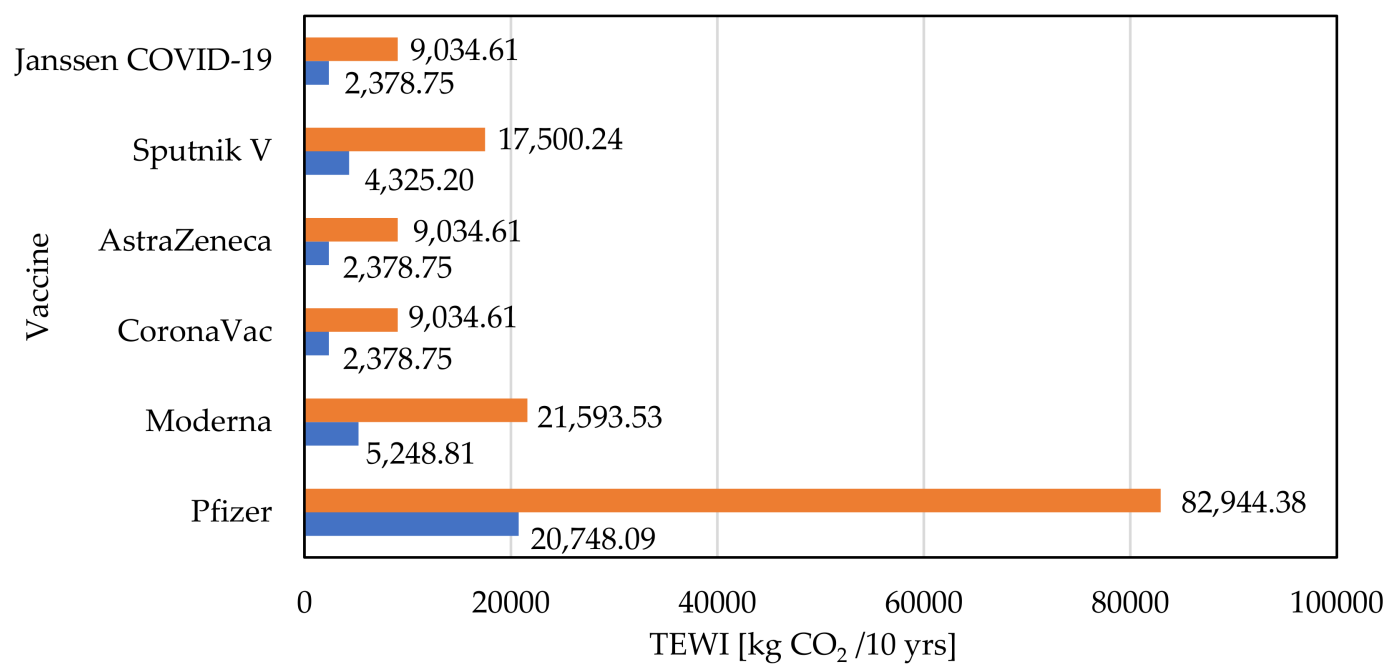

Figure 4. Comparison of TEWI values of 100,000 doses vaccine refrigeration in Brazil and the USA for 10 years. Legend: Brazil: $\square$; USA: $\square$.

\section{Analysis and Discussion of Results}

\subsection{Worldwide Vaccine EUED}

Assuming 14 billion doses, in two semiannual phases of seven billion doses-that is, equivalent to 70,000 in these refrigerators-the Vaccine EUED index worldwide is shown in Table 6. It is important to emphasize that this energy consumption is only related to vaccine cold conservation; it does not consider its manufacturing and transportation. There are several environmental impacts since these vaccines usually need low temperatures and are often transported by plane.

Table 6. Worldwide Vaccine EUED.

\begin{tabular}{cc}
\hline Vaccine & Vaccine EUED (MWh/yr) \\
\hline Pfizer-BioNTech & $1,323,325.5$ \\
Moderna & $347,760.0$ \\
CoronaVac & $141,614.2$ \\
Oxford-AstraZeneca & $141,614.2$ \\
Sputnik V & $280,319.9$ \\
Janssen COVID-19 & $141,614.2$ \\
\hline
\end{tabular}

In Brazil, the average annual energy consumption of each individual is $2294.8 \mathrm{kWh}$, and the energy needed to store the seven billion doses of Pfizer-BioNTech vaccine would be the same as that needed to annually power a city of 576,662 inhabitants. The same calculus for storing the seven billion doses of Oxford-AstraZeneca vaccine would similarly power a city of 61,710 inhabitants [35].

\subsection{Worldwide Vaccine TEWI}

There are several indications that the vaccine against COVID-19 should be administered annually, due to mutations in the virus [36]. In this case, the use of the Vaccine TEWI indicator in the lifecycle of a refrigeration system is the best way to apply the calculation for a simulation; a lifecycle of 10 years has been used.

Considering the same premise for the Vaccine EUED indicator to meet world demand, 70,000 active refrigerators for 10 years would be needed to acclimatize a demand of 
14 billion doses per year in two stages of seven billion semiannually, when comparing the values of Vaccine TEWI in Brazil and the USA; this is shown in Table 7.

Table 7. Worldwide Vaccine TEWI.

\begin{tabular}{ccc}
\hline Vaccine & TEWI Total Brazil (Ton $\left.\mathbf{C O}_{\mathbf{2}} \mathbf{1 0} \mathbf{~ y r}\right)$ & TEWI Total USA $\left._{\mathbf{~ T o n ~ C O}} \mathbf{~ 1 0 ~} \mathbf{~ y r}\right)$ \\
\hline Pfizer-BioNTech & $1,452,366.09$ & $5,806,106.98$ \\
Moderna & $367,416.47$ & $1,511,546.87$ \\
CoronaVac & $166,512.35$ & $632,423.06$ \\
Oxford-AstraZeneca & $166,512.35$ & $632,423.06$ \\
Sputnik V & $302,764.08$ & $1,225,016.55$ \\
Janssen COVID-19 & $166,512.35$ & $632,423.06$ \\
\hline
\end{tabular}

A 1.4-L motorized car running 20,000 km/yr emits approximately 7.32 tons of $\mathrm{CO}_{2}$. In this case, the emission by cars is shown in Table 8 [37]. The comparison with cars allows to compare easily point out the environmental impact of the refrigeration systems for the COVID 19 vaccines. The generation of $\mathrm{CO}_{2}$ by the refrigerated storage of vaccine from Pfizer-BioNTech in the USA would be equivalent to the circulation of 158,636 cars running $20,000 \mathrm{~km}$, and that the generation of $\mathrm{CO}_{2}$ by the refrigerated storage of vaccines from Oxford-AstraZeneca, CoronaVac and Janssen COVID-19 vaccine in Brazil would be equivalent to 4549 cars running the same length.

Table 8. $\mathrm{CO}_{2}$ generated by number of cars in Brazil and the USA.

\begin{tabular}{ccc}
\hline Vaccine & Number of Cars in Brazil & Number of Cars in the USA \\
\hline Pfizer-BioNTech & $39,682.13$ & $158,636.80$ \\
Moderna & $10,038.70$ & $41,299.09$ \\
CoronaVac & 4549.52 & $17,279.32$ \\
Oxford-AstraZeneca & 4549.52 & $17,279.32$ \\
Sputnik V & 8272.24 & $33,470.40$ \\
Janssen COVID-19 & 4549.52 & $17,279.32$ \\
\hline
\end{tabular}

Although Tables 6-8 compare the different vaccine brands for the same number of doses, it is important to highlight that the Janssen COVID-19 vaccine requires a single dose [38], while the others require two doses. So, its environmental impact is the lowest.

The same method could be extended to compare other types of vaccines that are under development.

\section{Conclusions}

This article shows quantitatively the differences between the electricity consumption and pollutant emissions of the refrigeration solutions for various COVID-19 vaccines. In addition to the financial and logistical difficulties, and the assumption that the value of a life cannot be defined, it becomes necessary to use these indicators to help in making important decisions concerning vaccine selection. The associated energy and environmental impact indexes, Vaccine EUED and Vaccine TEWI, respectively, to associate vaccine technologies with energy efficiency and sustainability will have a significant impact worldwide.

All simulations considered refrigerators in air-conditioned locations, but these investments in air-conditioned rooms and ultra-low-temperature refrigerators are rare in developing countries. Nevertheless, these logistical difficulties are also poignant in developed countries due to the delays in vaccination. Considering these options, policymakers should always prioritize low-impact technologies and this article proves that the measurement tools already exist.

The Vaccine EUED and the Vaccine TEWI indexes can be vital tools for decisionmaking in a second round of immunization as this situation will be the "new normal". 
Author Contributions: Conceptualization, A.F.S. and P.D.G.; methodology, A.F.S.; validation, A.F.S. and H.J.L.d.S.; formal analysis, A.F.S. and P.D.G.; investigation, A.F.S.; resources, H.J.L.d.S.; data curation, A.F.S. and P.D.G.; writing-original draft preparation, A.F.S., H.J.L.d.S.; writing-review and editing, P.D.G.; visualization, H.J.L.d.S.; supervision, P.D.G.; project administration, A.F.S. All authors have read and agreed to the published version of the manuscript.

Funding: This research received no external funding.

Institutional Review Board Statement: Not applicable.

Informed Consent Statement: Not applicable.

Data Availability Statement: Data can be found in the references cited in the manuscript.

Acknowledgments: Authors acknowledge Fundação para a Ciência e a Tecnologia (FCT-MCTES) for its financial support via the project UIDB/00151/2020 (C-MAST).

Conflicts of Interest: The authors declare no conflict of interest.

\section{References}

1. ABRAVA. Revista ABRAVA+Climatização E Refrigeração. Editora Novatécnica; ABRAVA: São Paulo, Brazil, 2021 ; ISSN $2358-8926$.

2. Ledford, H. Moderna COVID vaccine becomes second to get US authorization. Nature 2020. [CrossRef] [PubMed]

3. Kaoru, T.; Fernandes, D. Anvisa Approves Emergency Use of Oxford and Coronavac Vaccine; CNN: São Paulo, Brazil. Available online: https:/ / www.cnnbrasil.com.br/saude/2021/01/17/votos-anvisa-vacina-coronavac-oxford (accessed on 17 January 2021).

4. Gamba, L. Argentina 1st Latin American Nation to OK Sputnik Vaccine. Plane Expected to Bring 300,000 Doses of Vaccine to Country Thursday. Anadolu Agency. Available online: https:/ /www.aa.com.tr/en/americas/argentina-1st-latin-americannation-to-ok-sputnik-vaccine/2086848 (accessed on 9 February 2021).

5. Gewin, V. Safely Conducting Essential Research in the Face of COVID-19. Nature 2020, 580, 549-550. [CrossRef] [PubMed]

6. Pfizer. Covid-19 Vaccine U.S. Distribution Fact Sheet. Available online: https://www.pfizer.com/news/hot-topics/covid_19 _vaccine_u_s_distribution_fact_sheet (accessed on 10 February 2021).

7. CDC. Moderna COVID-19 Vaccine. Storage and Handling Summary. Available online: https://www.cdc.gov/vaccines/covid-19 /info-by-product/moderna/downloads/storage-summary.pdf (accessed on 9 February 2021).

8. CDC. Info by Product. Available online: https://www.cdc.gov/vaccines/covid-19/info-by-product/moderna/index.htm (accessed on 10 February 2021).

9. KIM, M.; LIU, R. Sinovac's COVID-19 Vaccine Induces Quick Immune Response Study; REUTERS: Toronto, ON, Canada, 2020.

10. Medicines \& Healthcare Products Regulatory Agency. Decision: Information for UK Recipients on COVID 19 Vaccine AstraZeneca; Medicines \& Healthcare Products Regulatory Agency: London, UK, 2021.

11. Jones, I.; Roy, P. Sputnik V COVID-19 Vaccine Candidate Appears Safe and Effective. Lancet 2021. [CrossRef]

12. CDC. Storage and Handling Summary. Available online: https://www.cdc.gov/vaccines/covid-19/info-by-product/janssen/ downloads/janssen-storage-handling-summary.pdf (accessed on 19 May 2020).

13. CDC. Pfizer-BioNTech COVID-19 Vaccine. Available online: https://www.cdc.gov/vaccines/covid-19/info-by-product/pfizer/ index.html (accessed on 10 February 2021).

14. COOLPACK. Software COOLPACK Version 1.49; IPU \& Department of Mechanical Engineering Technical University of Denmark: Lynby, Denmark, 2011.

15. ASHRAE 90.1. Standard 90.1-2019 (I-P Edition)_Energy Standard for Buildings Except Low-Rise Residential Buildings (ANSI Approved;IES Cosponsored); ASHRAE: Atlanta, GA, USA, 2019.

16. AHRI 1201-2013. Performance Rating of Commercial Refrigerated Display Merchandisers and Storage Cabinets (SI) (AHRI); AURI: Arlington, TX, USA, 2013.

17. AHRI 210/240-2017. Performance Rating of Unitary Air-Conditioning \& Air-Source Heat Pump Equipment; AHRI: Arlington, TX, USA, 2017.

18. ANSI/ASHRAE Standard 72-2018. Standard 72-2018-Method of Testing Open and Closed Commercial Refrigerators and Freezers (ANSI Approved); ANSI: Arlington, TX, USA, 2018.

19. EPA. International Actions-The Montreal Protocol on Substances that Deplete the Ozone Layer. United States Environmental Protection Agency-EPA. Available online: https://www.epa.gov/ozone-layer-protection/international-actions-montrealprotocol-substances-deplete-ozone-layer (accessed on 10 February 2021).

20. Unenviroment. The Kigali Amendment to the Montreal Protocol: HFC Phase-Down. Available online: https://www. unenvironment.org/ozonaction/resources/factsheet/kigali-amendment-montreal-protocol-hfc-phase-down (accessed on 10 February 2021).

21. IPCC. Fourth Assessment Report. 2021. Available online: https://www.ipcc.ch/assessment-report/ar4/ (accessed on 22 January 2021).

22. WHO. Guideline for Establishing or Improving Primary and Intermediate Vaccine Stores Vaccines and Biologicals; World Health Organization, Department of Vaccines and Biologicals, CH-1211: Geneva, Switzerland, 2002. 
23. OPTEON. Chemours Refrigerant Expert 1.0 Software. Available online: https://www.opteon.com/en/support/helpfulresources/refrigerant-expert-tool (accessed on 10 February 2021).

24. Santos, A.F.; Souza, H.J.L.; Cantão, M.P.; Gaspar, P.D. Analysis of temperatures for geothermal heat pumps application in Paraná (Brazil). In Proceedings of the International Conference on Engineering-Engineering for Society (ICEUBI2015), University of Beira Interior, Covilhã, Portugal, 3-4 December 2015; ISBN 978-989-654-261-0.

25. Santos, A.F.; Souza, H.J.L.; Cantão, M.P.; Gaspar, P.D. Analysis of temperatures for geothermal heat pumps application in Paraná (Brazil). Open Eng. 2016, 6, 485-491. [CrossRef]

26. Santos, A.F.; de Souza, H.J.L.; Gaspar, P.D. Avaliação do desempenho térmico e energético de um datacenter por um novo índice de eficiência: Energy Usage Effectiveness Design-EUED. In Proceedings of the $11^{\circ}$ Congresso Brasileiro de Ar Condicionado, Refrigeração, Aquecimento e Ventilação, Porto Alegre, Brazil, 25-27 September 2018.

27. Santos, A.F.; Gaspar, P.D.; Souza, H.J.L. Avaliação do desempenho térmico e energético de um datacenter por um novo índice de eficiência: Energy Usage Effectiveness Design-EUED. In Proceedings of the Congresso Brasileiro de Refrigeração, ArCondicionado, Ventilação, Aquecimento e Tratamento de Ar (XVI CONBRAVA), São Paulo, Brazil, 10-13 September 2019.

28. Santos, A.F.; de Souza, H.J.L.; Gaspar, P.D. Evaluation of the heat and energy performance of a datacenter by a new efficiency index: Energy Usage Effectiveness Design-EUED. In Proceedings of the 25th IIR International Congress of Refrigeration (ICR 2019), Montreal, QC, Canada, 24-30 August 2019. [CrossRef]

29. Santos, A.F.; de Souza, H.J.L.; Gaspar, P.D. Evaluation of the heat and energy performance of a datacenter for a new efficiency index: Energy Usage Effectiveness Design-EUED. Braz. Arch. Biol. Technol. 2019, 62. [CrossRef]

30. Santos, A.F.; Gaspar, P.D.; de Souza, H.J.L. New datacenter performance index: Perfect Design Datacenter-PDD. Climate 2020, 8, 110. [CrossRef]

31. Santos, A.F.; Gaspar, P.D.; Souza, H.J.L. New index for Sustainability-TWI (Total Water Impact). Energies 2020, 13, 1590. [CrossRef]

32. Santos, A.F.; Gaspar, P.D.; de Souza, H.J.L. Ecoenergetic simulation of HVAC systems in Data Centers. Climate 2021, 9, 42. [CrossRef]

33. AHRI Standard 1361 (SI). 2017 Standard for Performance Rating of Computer and Data Processing Room Air Conditioners; AHRI: Arlington, VA, USA, 2017.

34. EPE. Balanço Energético Nacional 2019. Relatório Síntese / Ano Base 2018. Ministério de Minas e Energia—MME/Empresa de Pesquisa Energética-EPE. 2019. Available online: https:/ /www.epe.gov.br/sites-pt/publicacoes-dados-abertos/publicacoes/ PublicacoesArquivos/publicacao-377/topico-470/Relat\%C3\%B3rio\%20S\%C3\%ADntese\%20BEN\%202019\%20Ano\%20Base\% 202018.pdf (accessed on 10 February 2021).

35. EPE. Anuário Estatístico de Energia Elétrica 2020. Ano Base 2019. Available online: https://www.epe.gov.br/sites-pt/ publicacoes-dados-abertos/publicacoes/PublicacoesArquivos/publicacao-160/topico-168/EPEFactSheetAnuario.pdf (accessed on 10 February 2021).

36. CNBC. J\&J CEO Says People May Need Annual Covid Vaccine Shots for the Next Several Years. 2021. Available online: https:// www.cnbc.com/2021/02/09/covid-vaccine-jj-ceo-says-people-may-get-annual-shots-for-the-next-several-years.html (accessed on 9 February 2021).

37. ECCAPLAN. Calculadora Para Emissão de Carbono. Available online: https://calculadora.eccaplan.com.br/ (accessed on 10 February 2021).

38. Ledford, H. J\&J's One-Shot COVID Vaccine Offers Hope for Faster Protection. Nature 2021. Available online: https://www, nature.com/articles/d41586-021-00119-7 (accessed on 21 March 2021). [CrossRef] 